\title{
Post-Stroke Working Memory Dysfunction: A Meta-Analysis and Systematic Review
}

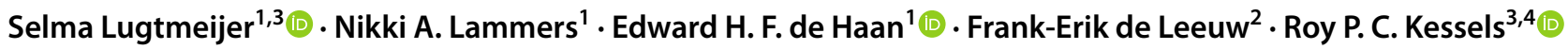

Received: 17 October 2019 / Accepted: 7 October 2020 / Published online: 24 November 2020

(c) The Author(s) 2020

\begin{abstract}
This review investigates the severity and nature of post-stroke working memory deficits with reference to the multi-component model of working memory. We conducted a systematic search in PubMed up to March 2019 with search terms for stroke and memory. Studies on adult stroke patients, that included a control group, and assessed working memory function, were selected. Effect sizes (Hedges' $g$ ) were extracted from 50 studies (in total 3,084 stroke patients) based on the sample size, mean and standard deviation of patients and controls. Performance of stroke patients was compared to healthy controls on low-load (i.e. capacity) and high-load (executively demanding) working memory tasks, grouped by modality (verbal, nonverbal). A separate analysis compared patients in the sub-acute and the chronic stage. Longitudinal studies and effects of lesion location were systematically reviewed. Stroke patients demonstrated significant deficits in working memory with a moderate effect size for both low-load (Hedges' $g=-.58$ [-.82 to -.43]) and high-load (Hedges' $g=-.59$ [-.73 to -.45]) tasks. The effect sizes were comparable for verbal and non-verbal material. Systematically reviewing the literature showed that working memory deficits remain prominent in the chronic stage of stroke. Lesions in a widespread fronto-parietal network are associated with working memory deficits. Stroke patients show decrements of moderate magnitude in all subsystems of working memory. This review clearly demonstrates the global nature of the impairment in working memory post-stroke.
\end{abstract}

Keywords Stroke $\cdot$ Cognition $\cdot$ Working memory $\cdot$ Prevalence $\cdot$ Systematic review $\cdot$ Meta-analysis

\section{Introduction}

Selma Lugtmeijer

S.Lugtmeijer@uva.nl

Nikki A. Lammers

N.A.Lammers@uva.nl

Edward H. F. de Haan

E.H.F.deHaan@uva.nl

Frank-Erik de Leeuw

FrankErik.deLeeuw@ radboudumc.nl

Roy P. C. Kessels

R.Kessels@donders.ru.nl

1 University of Amsterdam, Amsterdam, the Netherlands

2 Radboud University Medical Center, Department of Neurology, Nijmegen, the Netherlands

3 Donders Institute for Brain, Cognition and Behaviour, Radboud University, Nijmegen, the Netherlands

4 Department of Medical Psychology, Radboud University Medical Center, Nijmegen, the Netherlands
Stroke survivors may be challenged not only with physical disability, but also with cognitive consequences. Dysfunction in perception, executive functioning, abstract reasoning, episodic memory or language has been found to be present in $60-70 \%$ of stroke patients (Nys, Van Zandvoort, Worp, Kappelle, \& Haan, 2007; De Haan, Nys, \& Van Zandvoort, 2006). Post-stroke cognitive impairment has been associated with functional dependency (e.g. Saxena, Ng, Koh, Yong, \& Fong, 2007) and poorer quality of life (e.g. Mellon, Brewer, Hall, Horgan, Williams, \& Hickey, 2015). Whereas post-stroke dementia and episodic memory function after stroke have been abundantly studied and reviewed (see, for instance, reviews by Pendlebury \& Rothwell, 2009, and Lim $\&$ Alexander, 2009, respectively), a comprehensive overview of working memory deficits as a consequence of stroke is lacking. This is striking, as working memory/updating is considered to be one of the key subdomains of executive function along with shifting and inhibition (see e.g. comprehensive reviews by Chan, Shum, Toulopoulou, \& Chen, 
2008 and Friedman \& Myake, 2017). Deficits in this memory system may not only affect other executive functions, but also episodic memory formation and retrieval (Bergmann, Kiemeneij, Fernández, \& Kessels, 2013). Furthermore, a recent prospective cohort study on cognitive function and long-term functional outcome after stroke at a young age $(<50)$ showed that only decline in working memory predicted poor functional outcome 11 years after the stroke (Synhaeve, Schaapsmeerders, Arntz, Maaijwee, RuttenJacobs, Schoonderwaldt, \& de Leeuw, 2015).

Working memory is generally thought of as a multicomponent system involved in goal-directed behaviour that involves retaining and manipulating information (Baddeley, Hitch, \& Allen, 2018; Chai, Abd Hamid, \& Abdullah, 2018). A prominent model is that of (Baddeley and Hitch, 1974, Baddeley, 2000). The model describes four subcomponents: the phonological loop (based on vocalisation and rehearsal), visuospatial sketchpad (for visuo-spatial rehearsal), the central executive, and the episodic buffer (Baddeley, 2012). The limited capacities of the phonological loop and the visuospatial sketchpad are measured by tasks that require passive maintenance of verbal and visuo-spatial information respectively (often referred to as short-term memory). Frequently used tasks to assess short-term memory capacity are forward span tasks. The involvement of the central executive, which can be described as the attentional control system, is measured by working memory tasks that involve both maintenance and processing, for example backward span tasks. The episodic buffer is responsible for the binding of information in working memory, and linking working memory to perception and long-term memory (Baddeley, 2000). This buffer is difficult to assess by standardized and process-pure tasks (Nobre, Rodrigues, Sbicigo, Piccolo, Zortea, Junior, \& de Salles, 2013) and its exact nature and properties have also been under debate (Heil, Rösler, \& Rolke, 2003).

One of the reasons why there is no clear understanding of post-stroke working memory deficits is the heterogeneity in patient populations studied with respect to lesion locations, timing of assessment and small sample sizes. A second reason is that most studies only assess one component of working memory. A recent study (Karimian, Asgari, Neshat Doost, Oreizi, \& Najafi, 2018) that investigated short-term memory, working memory, and long-term memory in the verbal, visuo-spatial, and visual domains in 35 stroke patients reports memory impairment on all aspects assessed. Most pronounced were impairments in visual short-term and long-term memory. A study by Nys and colleagues (2007) including 168 stroke patients reported a slightly higher percentage of patients with verbal memory impairment compared to visual memory impairment $25.6 \%$ and $22 \%$ respectively). In turn, a study in 39 acute stroke patients (Roussel, Dujardin, Hénon, \& Godefroy, 2012) that investigated whether impairment in working memory remains after controlling for short-term memory capacity indicated that working memory impairment is a consequence of reduced short-term memory capacity.

A potential moderator of post-stroke working memory performance might be the time that elapsed since stroke. There is no consensus in the literature on working memory function in the chronic stage of stroke. For example, Kant, van den Berg, van Zandvoort, Frijns, Kappelle, \& Postma, (2014) reported differences between chronic stroke patients and controls on all three working memory tasks they included, while McDonnell et al. (2011) did not find any differences between patients and controls. Yet another study (Andrade, Brucki, Bueno, \& Siqueira Neto, 2012) reported only decreased working memory performance in patients who were classified as having post-stroke vascular dementia.

Although there is clear evidence that working memory is affected at least in the acute stage of stroke, a detailed analysis is lacking as to whether these deficits concern the different components and processing modes of the working memory system to a similar extent. Unravelling this in stroke patients is crucial as subsystems of working memory are essential for many other cognitive processes and may be closely related to functional outcome. The primary objective of this meta-analysis and systematic review is to quantify the severity of post-stroke working memory impairment by comparing patients to stroke-free controls. Specifically disentangling the effects for low-load working memory tasks (mainly addressing the passive limited capacity store) and more cognitively demanding high-load working memory tasks (involving executive processing). We will also systematically compare outcomes in the verbal and non-verbal domains, and in the sub-acute and chronic stages of stroke. A secondary objective is to identify possible associations between post-stroke working memory impairment and lesion location. As patient studies often have small samples and most studies do not include different aspects of working memory, quantitatively reviewing all available studies on this topic will help to provide a more comprehensive picture of working memory deficits after stroke.

\section{Method}

PRISMA guidelines were used for the reporting of this systematic review (checklist provided in Appendix 1, Table 2; Moher, Liberati, Tetzlaff, \& Altman, The PRISMA Group, 2009).

\section{Data Sources}

Electronic database Pubmed was searched for relevant studies; last search was performed on 10-03-2019. The following search terms were used: "stroke", "post-stroke", "cva", "cerebrovascular accident", "cerebral vascular accident", 
"brain infarct*”, "cerebral infarct*”, "brain lesion", "ischemic lesion", "cerebral ischemia", "tia”, "transient ischemic attack" AND "memory disorders", "memory", "cognitive domain*". Reference lists of selected articles were searched for potential missed articles.

\section{Study Selection and Eligibility Criteria}

A two-step approach was used to select articles. Firstly, titles and abstracts of all search results were screened for the following characteristics by one reviewer (S.L.): (1) original article published in English, (2) participants are adults ( $>18$ years of age), (3) study concerning stroke or transient ischemic attack (TIA) patients, (4) sample size of at least 10 patients, as single-case studies or case series often concern rare cases whose behaviour might not be representative for the larger stroke patient population (5) outcome measures or descriptives include at least one working memory task; in case the abstract only mentioned memory function in general, the article was selected for full-text evaluation, (6) studies that only included patients with (subjective) memory complaints were excluded.

Secondly, 543 full-text articles were obtained from the selected studies and were reviewed on the following inclusion criteria: (7) a stroke-free control group was included as comparison, (8) clinical stroke patients in the sample (9) working memory function measured with a formal test or clearly described experimental paradigm, (10) treatment studies are included when baseline measures are reported. When two or more publications referring to the same sample were available, we extracted data only from the publication presenting the most accurate estimate, either because of sample size or outcome assessment. Two authors (S.L. and N.A.L.) independently performed the second step of the selection process. A meeting was held in case of disagreement which in all cases led to consensus.

Studies that included TIA patients were included in the meta-analysis as post-TIA cognitive impairment is often reported. A systematic review by Van Rooij, Kessels, Richard, De Leeuw, \& van Dijk (2016) including 13 studies with data from 1,318 TIA patients, concluded that mild cognitive impairment is present in over a third of the TIA patients. When a mixed etiology lesion population was tested, the study was only included if separate results for the stroke patients could be retrieved.

\section{Data Extraction and Synthesis}

Performance on working memory tests as compared to a healthy control group were extracted, as were participant characteristics, specific in- and exclusion criteria, and timing of assessment. First, overall performance on working memory tests was compared between stroke patients and healthy controls. Second, performances on low-load and high-load tasks were compared with a distinction between verbal and non-verbal tasks. Tests were considered low-load if they rely on remembering a limited amount of information over a short time, such as forward digit or spatial span tasks. In the working memory model of Baddeley and Hitch (1974) this is based on the phonological loop for verbal information and the visuo-spatial sketchpad for non-verbal information. Tasks that were considered high-load required some form of manipulation or updating, such as backward span or sequencing tasks, based on the central executive of the model. Tasks in which the stimuli (either visually or auditory) were digits, words, sentences or stories were categorized as verbal in nature. Tests were nonverbal in nature if stimuli were pictures of objects, scenes, line drawings or abstract figures. Third, a sub-analysis was conducted to examine the effect of timing of assessment (i.e. duration post stroke). Assessment within the first three months after stroke was considered sub-acute. Assessment after three months was considered as chronic. Qualitative synthesis of study results was performed with attention to lesion location. Working memory performance was compared between studies with specific inclusion criteria based on lesion location or imaging analyses relating lesion location to working memory performance. Working memory performance was compared within studies that selected groups based on lesion location.

\section{Risk of Bias Assessment}

Risk of bias assessment was performed with the Research Triangle Institute (RTI) item bank, a tool to evaluate the bias and quality of observational studies (Viswanathan \& Berkman, 2012; Viswanathan, Berkman, Dryden, \& Hartling, 2013). As suggested by the RTI developers, slight adjustments were made to match the designs of the included studies (Appendix 2). Four items were dropped and items were reformulated to fit a case-control design. Ten items that assessed the selection bias, detection bias, attrition bias, selective outcome reporting and confounding were selected.

\section{Statistical Analysis}

For the meta-analysis, sample sizes, means and standard deviations from the working memory tests were extracted from the studies. If necessary, corresponding authors were contacted to obtain these statistics based on the raw data. Summary statistics (Hedges' $g$ ) were calculated based on sample sizes $(N)$, means of patients and controls $(M)$ and standard deviations $(S D)$ with the following formula: $g=$ StdDiff $\times J$. StdDiff was calculated using the following formula: $(M 1-M 2) / S D_{\text {pooled }}$, with $S D_{\text {pooled }}=\sqrt{ }(((N 1$ 1) $\left.\left.\times S D 1^{\wedge} 2+(N 2-1) \times S D 2^{\wedge} 2\right) /(N 1+N 2-2)\right)$. The 
correction factor for different sample sizes is $J$, that was calculated as: $1-(3 /(4 \times \mathrm{df}-1))$, where $\mathrm{df}=N 1+N 2-$ 2. Pooled variance was calculated by: $\sqrt{ }(1 / N 1+1 /$ $N 2) \times S D_{\text {pooled. }}$ In case more than one outcome measure was reported, the average ES was calculated for the overall analysis. By using the mean of different outcome measures to calculate the effect size of the study we assume a correlation of 1 between different measures. This is a conservative approach as the actual correlation is probably less than 1 and the variance is lower than what we assume. The alternative is treating every outcome measure as fully independent, assuming a correlation of 0 , which results in underestimation of variance of the summary effect size. The actual overall effect size might therefore be slightly higher than our estimate. For the mixed-effect analyses of the effect of load and modality it was necessary to assume independence of outcome measures. Effect sizes were interpreted according to Cohen's (1992) convention of small (0.20), medium $(0.50)$, and large (0.80) effects for positive and negative values. Performance of stroke patients is lower compared to controls if the effect size (ES) is negative. Bias due to small sample sizes was corrected for by including sample size as a weighting factor (Hedges \& Olkin, 1985). Random-effects models were used because of heterogeneity in populations studied and in outcome measures. Additionally, the goal is to generalize the results beyond the observed studies (Borenstein, Hedges, Higgins, \& Rothstein, 2011). Heterogeneity was checked for by the use of the chi-square homogeneity test (Q). The fail-safe $N$ was calculated for each study and a funnel plot was made (Rosenthal, 1991). The fail-safe $N$ must to be larger than $(5 \times k)+10$, where $k$ refers to the number of studies included in the meta-analysis (Clark-Carter, 2010). This measure gives an indication of how many studies with null-results should be unpublished due to publication bias to nullify the effect. All analyses were performed using Comprehensive Meta-Analysis version 2.0 (Engelwood, NJ, USA, 2005).

\section{Results}

\section{Selection of Articles}

The literature search resulted in 4,318 articles after removal of duplicates. Seven additional studies where identified by manually checking of reference lists of selected papers. In total, 553 were selected for full text screening. Seventy-five articles published between 1992 and early 2019 were eligible for inclusion. The eventual meta-analysis includes data of 3,084 stroke patients from 50 studies. An additional 25 studies of which the necessary statistics could not be retrieved or studies with overlapping samples but with relevant subgroup analyses were included in the systematic review. Figure 1 shows the flowchart of the literature search. Table S1 (online supplemental materials) shows the details of the studies included, these are: sample size and specific inclusion criteria, stroke type, age, interval between stroke and assessment, inclusion of prior stroke patients, inclusion of patients with pre-existing dementia, task load, task, Hedges $g$, and variance, and number of effect sizes for each primary study.

\section{Description of Study Populations}

Ischemic stroke was the inclusion criterion for $30.6 \%$ $(k=23)$ of the studies. A quarter of the studies $(24.0 \%$, $k=18$ ) included both patients with haemorrhagic and ischemic stroke. Concerning studies that included TIA patients and minor stroke, 5.3\% $(k=4)$ included both stroke and TIA patients, $2.7 \%(k=2)$ reported on patients with minor stroke, ${ }^{1}$ and $2.7 \%(k=2)$ included only patients with transient ischemic attack (TIA). One study $(1.3 \%, k=1)$ included only patients with haemorrhagic stroke. A third $(33.3 \%, k=25)$ did not specify stroke type. A majority of the studies $(61.3 \%, k=46)$ did not select patients based on stroke location. Some studies $(14.7 \%, k=11)$ included only patients with subcortical lesions. Only one community-based study was fulfilled the inclusion criteria, all other studies were hospital- or rehabilitation center-based. Twenty percent $(k=10)$ studies included in the meta-analysis reported only one working memory measure. The mean number of outcome measures per study was 3.56. The maximum F number of outcome measures per study was 14 . Comparisons between left and right hemisphere stroke were made in $16 \%$ of the studies $(k=12)$. Few studies included patients with stroke in one specific hemisphere (left: $6.7 \%, k=5$, right: $9.3 \%, k=7$ ). A total of 50 authors were approached to obtain additional information and necessary statistics from tasks separately $(42.0 \%, k=21)$, from stroke patients separately $(12.0 \%, k=6)$, means and standard deviations that were not reported $(32 \%, k=16)$, clarification on tasks or population $(14 \%, k=7)$. This resulted in 16 studies that could be included in the meta-analysis. Of the 34 articles of which the authors did not respond, 22 were included in the qualitative analyses.

\section{Risk of Bias Assessment}

Risk of bias assessment of individual studies based on the RTI items (see Appendix 2 and online supplemental

\footnotetext{
${ }^{1} \mathrm{Li}$, You, Xu, Yuan, Shen, Huang, \& Liu (2019) defined minor stroke by a score of 5 or less on the National Institute of Health Stroke Scale at admission and a diagnosis of ischemic stroke confirmed by neuroimaging; Mansueti, De Frias, Bub, and Dixon (2008) based inclusion on self-reported mild stroke for which medical attention was received, in a community-based study.
} 


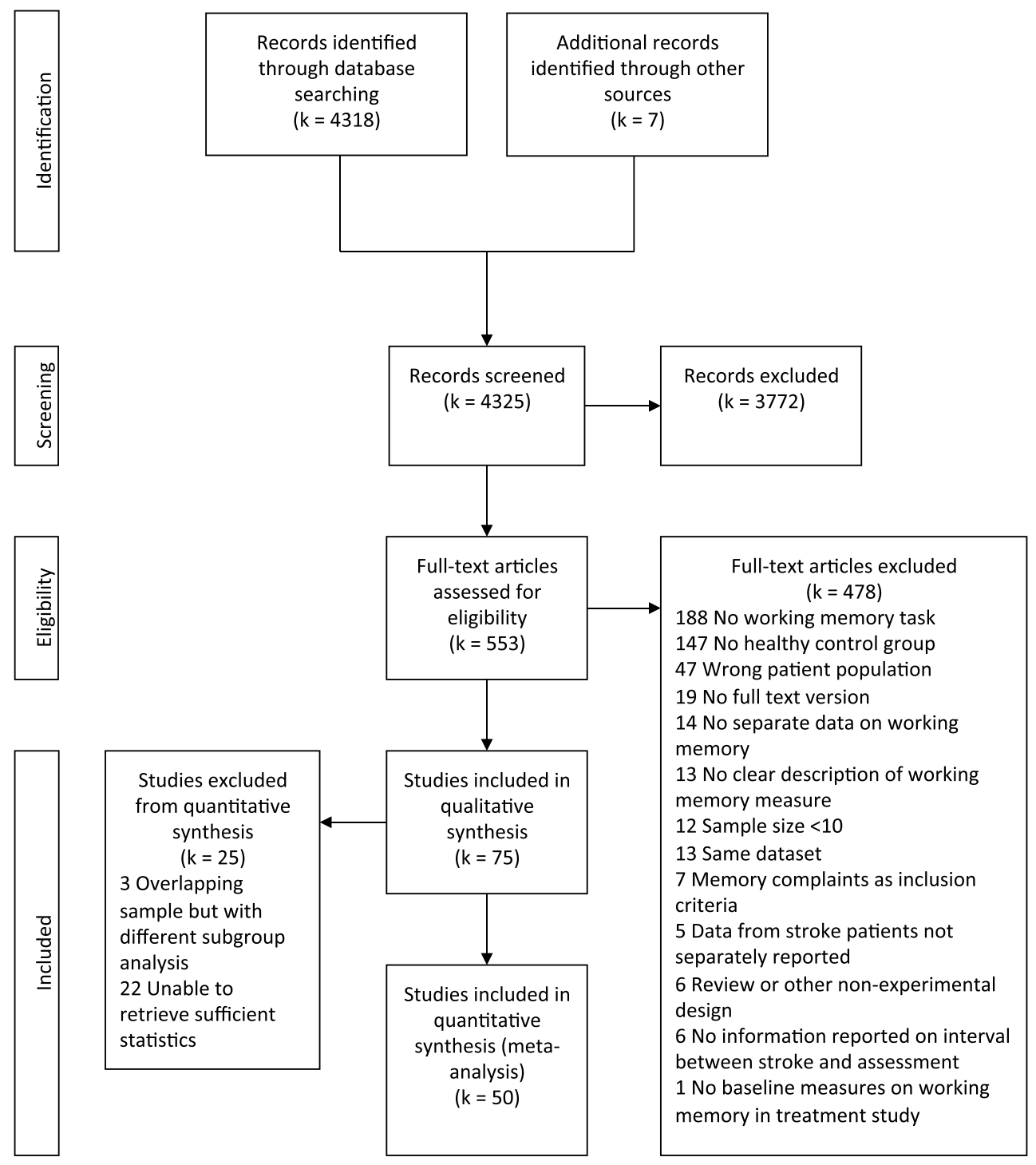

Fig. 1 PRISMA Flowchart

materials Table S2) showed an unclear or high risk of confounding, as in more than two-third $(72.0 \%, k=54)$ of the studies details on possible prior strokes or preexisting dementia were not specified, and in almost half $(56.7 \%, k=35)$ of the studies, in- and exclusion criteria for healthy controls were unclear. Although not invalidating the results of individual studies, it increased between-study heterogeneity. A majority of the studies $(72.0 \%, k=54)$ did include an age and education matched healthy control group. A second source of heterogeneity is the large variability in the intervals between stroke and assessment, both between and within studies. Almost all studies bear the risk of confirmation bias; only $5 \%$ of the studies $(k=4)$ reported that assessors were blinded to the status of the participant (patient or control). As deficits are often prominent, it is unsurprising that other studies did not report assessors to be naive to the participants group. The funnel plot shows the relation between the sample size and the effect size (Fig. 2). The plot shows some asymmetry, which may partly be due to heterogeneity in outcome measures and partly be due to publication bias. Especially the lower right corner is empty, which indicates that there are no small studies with small effect sizes. The summary statistics of the meta-analysis as shown in Table 1 includes the Fail-safe $N$ for each analysis as the number of studies with an effect size of zero that should be added to lose the significant result. All analyses have a Fail-safe $N$ larger than the pre-set criterion, indicating that it is unlikely that the effect is only significant because of publication bias. 
Fig. 2 Funnel plot

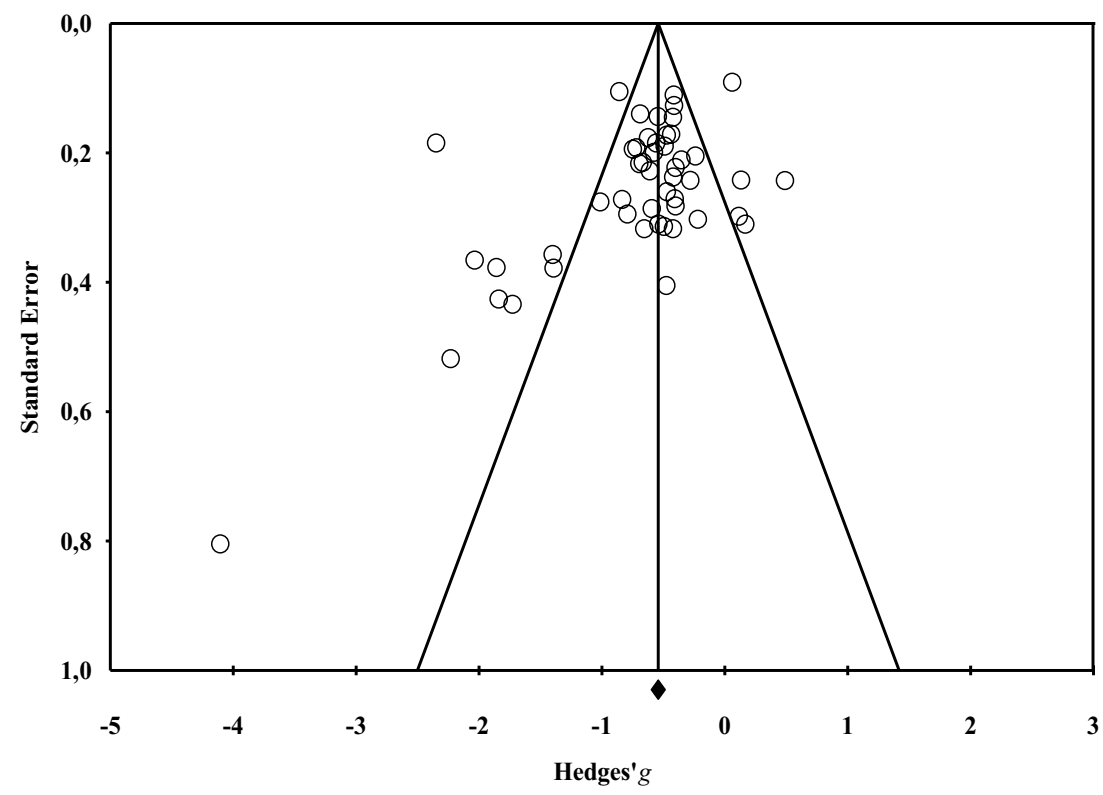

Table 1 Results of the metaanalyses

\begin{tabular}{llllllllll}
\hline & $k$ & $N P / H C$ & $E S(g)$ & $95 \% C I$ & $Q$ & $p(Q)$ & $I^{2}$ & $\tau^{2}$ & Fail-safe $N$ \\
\hline Overall & 50 & $3,084 / 2,898$ & -0.65 & -0.80 to -0.51 & 287.86 & $<0.001$ & 82.98 & 0.21 & 4,949 \\
Low- load & 39 & $2,699 / 2,318$ & -0.58 & -0.77 to -0.40 & 308.16 & $<0.001$ & 87.67 & 0.28 & 2,411 \\
High- load & 41 & $2,475 / 2,308$ & -0.59 & -0.73 to -0.45 & 171.72 & $<0.001$ & 76.71 & 0.14 & 2,783 \\
Sub-acute & 14 & $830 / 466$ & -0.43 & -0.68 to -0.19 & 45.80 & $<0.001$ & 71.62 & 0.15 & 144 \\
Chronic & 22 & $1,165 / 1,377$ & -0.90 & -1.15 to -0.65 & 157.25 & $<0.001$ & 86.65 & 0.29 & 1,740 \\
\hline
\end{tabular}

Note. $k=$ number of studies; $\mathrm{P}=$ patients; $\mathrm{HC}=$ healthy controls.

\section{Overall Effect, Effect of Memory Load, Modality and Timing of Assessment}

Analysis of data from 50 studies including 3,084 patients and 2,898 healthy controls on working memory averaged across tasks resulted in an overall moderate ES of -0.65 ([ -0.80 to -0.51$], p<0.001)$ for lower working memory performance in stroke patients. Thirty-nine studies (78\%) included a lowload working memory task. The analysis showed a moderate ES of -0.58 ([-0.77 to -0.40$], p<0.001)$. Analysis of forty-one studies $(82 \%)$ with a high-load working memory task resulted in a comparable $\mathrm{ES}$ of -0.59 ([-0.73 to -0.45$]), p<0.001)$. Figures 3 and 4 show the effect sizes per study grouped by modality under high and low-load conditions separately. Analyses show medium effect sizes $(<-0.50)$ in the verbal domain for high-load (-0.63) and low-load (-0.53) tasks and for low-load $(-0.62)$ tasks in the non-verbal domain. For high-load nonverbal tasks the effect size was slightly lower (-0.43). In order to compare the effect of low- and high-load we needed to assume independence of outcome measures. A mixed-effects meta-analysis shows a $Q$ statistic for the difference between the effect-sizes of $0.009(p=0.922)$, indicating that there were neither differences in effect sizes between low- and high-load tasks, nor differences in effect sizes for non-verbal and verbal tasks (high-load $Q=2.16, p=0.142$; low-load $Q=0.24$, $p=0.626$ ). To examine the effect of interval between stroke onset and assessment, a secondary analysis was performed. For this analysis we excluded studies that analysed patients in the sub-acute and chronic stage as one group. Fourteen studies $(28 \%)$ included patients in the sub-acute stage. The analysis showed a moderate ES of -0.43 ([-0.68 to -0.19$]$, $p<0.001)$. For patients in the chronic stage $(k=22,44 \%)$ the ES was large, -0.90 ([-1.15 to -0.65$], p<0.001$, Fig. 5). A mixed-effects analysis showed that this difference in effectsizes is statistically significant, $Q=6.88, p=0.009$. Patients in the chronic stage show more decrement in working memory performance compared to healthy controls than patients in the sub-acute stage. The heterogeneity indices $(Q)$ were all statistically significant $(p<0.05)$ for all analyses, indicating variation in study outcomes. The between study variance $(\tau$ ${ }^{2}$ ) of all studies is estimated as 0.21 . The $\mathrm{I}^{2}$ of 82.98 indicates that most of the observed variance reflects differences in study effect rather than sampling error. Results of the overall analysis and sub-analyses are presented in Table 1. Exclusion of studies that included patients with TIA did not lead to different results (Table S3a online supplemental materials). 
Fig. 3 Performance on low-load tasks categorized by modality (verbal and non-verbal)

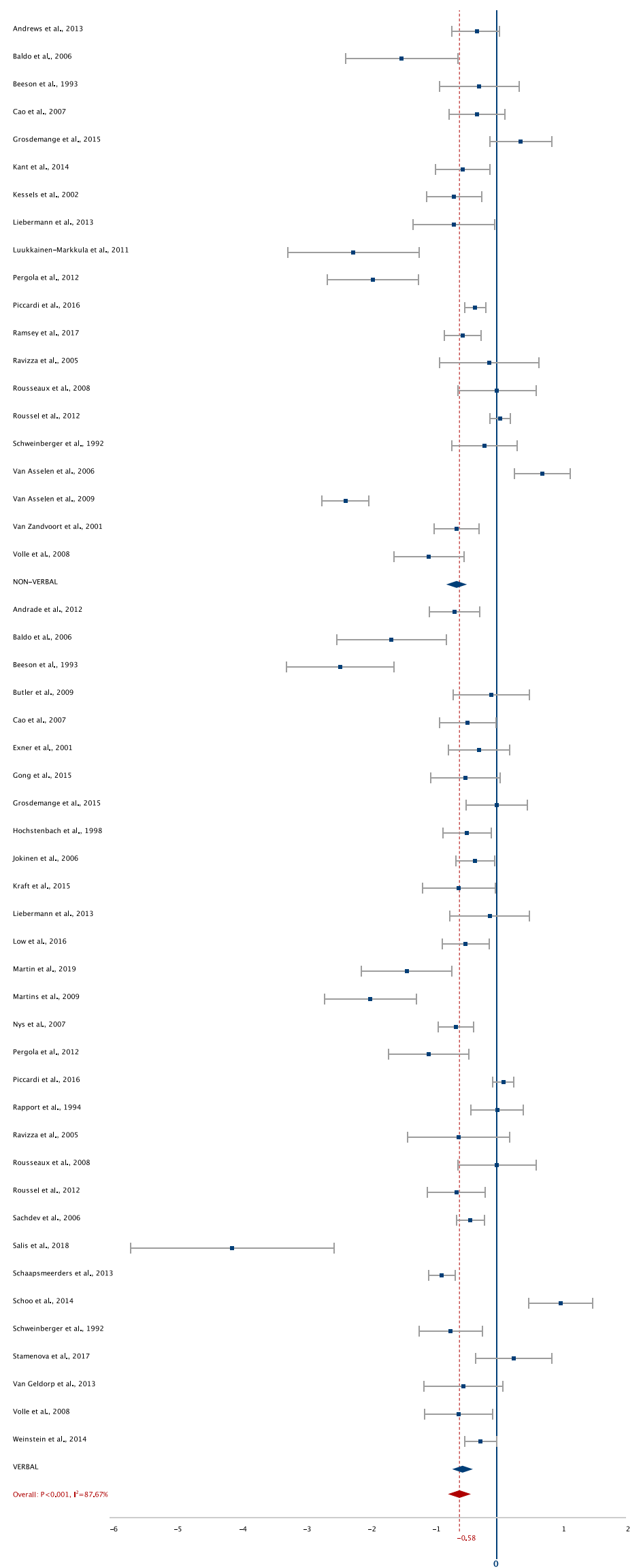

Hedges' $g \quad 95 \%$ Cl

$\begin{array}{lll}-0.33 & -0.7 & 0.04\end{array}$

$\begin{array}{lll}-1.47 & -2.34 & -0.6\end{array}$

$\begin{array}{lll}-0.27 & -0.89 & 0.35\end{array}$

$\begin{array}{lll}-0.31 & -0.74 & 0.13\end{array}$

$0.37 \quad-0.11 \quad 0.85$
0

$\begin{array}{lll}-0.53 & -0.95 & -0.11\end{array}$

$\begin{array}{lll}-0.66 & -1.08 & -0.24\end{array}$

$\begin{array}{lll}-0.67 & -1.3 & -0.03\end{array}$

$\begin{array}{lll}-2.22 & -3.24 & -1.21\end{array}$

$\begin{array}{lll}-1.92 & -2.62 & -1.21\end{array}$

$\begin{array}{lll}-0.33 & -0.49 & -0.1\end{array}$

$\begin{array}{lll}-0.53 & -0.81 & -0.24\end{array}$

$\begin{array}{lll}-0.12 & -0.89 & 0.66\end{array}$

$\begin{array}{lll}0 & -0.61 & 0.61\end{array}$

$\begin{array}{lll}-0.65 & -0.11 \quad 0.21\end{array}$

$\begin{array}{lll}-0.19 & -0.69 & 0.31\end{array}$

$\begin{array}{lll}0.7 & 0.27 & 1.13\end{array}$

$\begin{array}{lll}-2.34 & -2.71 & -1.98\end{array}$

$\begin{array}{lll}-0.62 & -0.97 & -0.27\end{array}$

$\begin{array}{rrr}-1.05 & -1.6 & -0.51\end{array}$

$\begin{array}{lll}-0.62 & -0.92 & -0.32\end{array}$

$\begin{array}{lll}-0.65 & -1.05 & -0.26\end{array}$

$\begin{array}{lll}-1.63 & -2.48 & -0.78\end{array}$

$\begin{array}{lll}-2.42 & -3.25 & -1.59\end{array}$

$\begin{array}{lll}-0.09 & -0.68 & 0.51\end{array}$

$\begin{array}{lll}-0.45 & -0.89 & -0.01\end{array}$

$\begin{array}{lll}-0.28 & -0.75 & 0.2\end{array}$

$\begin{array}{lll}-0.49 & -1.02 & 0.05\end{array}$

$\begin{array}{lll}0 & -0.47 \quad 0.48\end{array}$

$\begin{array}{lll}-0.47 & -0.84 & -0.09\end{array}$

$\begin{array}{llll}-0.3 & -0.64 & -0.04\end{array}$

$\begin{array}{lll}-0.59 & -1.15 & -0.03\end{array}$

$\begin{array}{lll}-0.11 & -0.73 & 0.51\end{array}$

$\begin{array}{llll}-0.48 & -0.84 & -0.12\end{array}$

$\begin{array}{lll}-1.4 & -2.1 & -0.69\end{array}$

$-1.96 \quad-2.67 \quad-1.25$

$\begin{array}{lll}-0.64 & -0.91 & -0.36\end{array}$

$\begin{array}{lll}-1.05 & -1.67 & -0.43\end{array}$

$\begin{array}{lll}0.1 & -0.06 & 0.26\end{array}$

$\begin{array}{lll}0 & -0.4 & 0.41\end{array}$

$\begin{array}{lll}-0.6 & -1.39 & 0.2\end{array}$

$\begin{array}{lll}-0.61 & 0.61\end{array}$

$\begin{array}{lll}-0.63 & -1.08 & -0.18\end{array}$

$\begin{array}{lll}-0.41 & -0.63 & -0.19\end{array}$

$\begin{array}{lll}-4.1 & -5.68 & -2.52\end{array}$

$-0.85 \quad-1.06 \quad-0.64$

$0.99 \quad 0.5 \quad 1.48$

$\begin{array}{lll}-0.75 & -1.21 & -0.23\end{array}$

$\begin{array}{llll}0.26 & -0.33 & 0.85\end{array}$

$\begin{array}{lll}-0.52 & -1.13 & 0.09\end{array}$

$\begin{array}{lll}-0.59 & -1.12 & -0.07\end{array}$

$\begin{array}{lll}-0.25 & -0.5 & -0.01\end{array}$

$\begin{array}{lll}-0.53 & -0.72 & -0.34\end{array}$

$\begin{array}{lll}-0.58 & -0.82 & -0.43\end{array}$ 
Fig. 4 Performance on highload tasks categorized by modality (verbal and nonverbal)

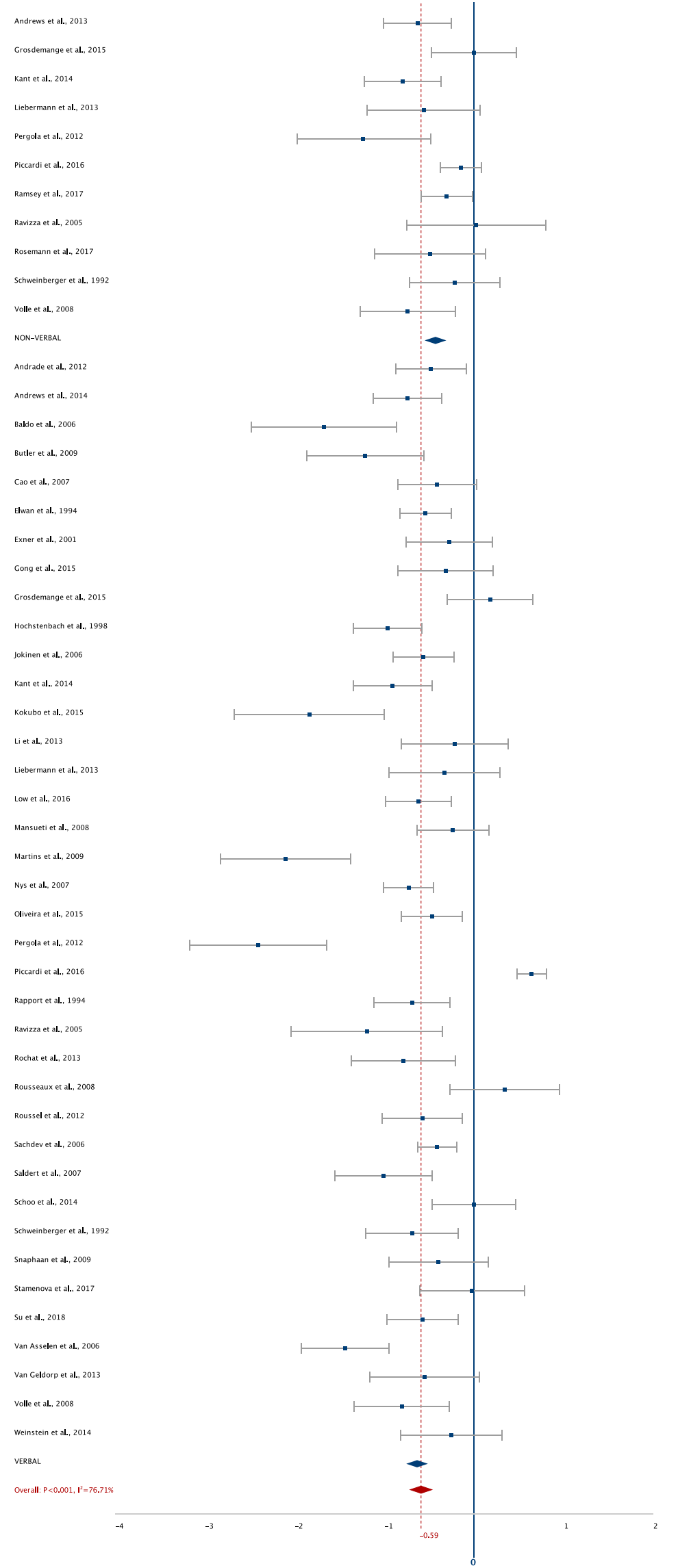

Hedge's $955 \%$ ic

$\begin{array}{lll}-0.63 & -1.01 & -0.25\end{array}$

$\begin{array}{lll}0 & -0.47 & 0.48\end{array}$

$\begin{array}{lll}-0.8 & -1.23 & -0.37\end{array}$

$\begin{array}{lll}-0.56 & -1.19 & 0.07\end{array}$

$\begin{array}{lll}-1.23 & -1.97 & -0.48\end{array}$

$\begin{array}{lll}-0.15 & -0.37 & 0.08\end{array}$

$\begin{array}{lll}-0.3 & -0.59 & -0.02\end{array}$

$\begin{array}{lll}0.03 & -0.75 & 0.8\end{array}$

$\begin{array}{lll}-0.49 & -1.11 & 0.13\end{array}$

$\begin{array}{lll}-0.21 & -0.72 & 0.29\end{array}$

$\begin{array}{lll}-0.74 & -1.27 & -0.21\end{array}$

$\begin{array}{lll}-0.43 & -0.62 & -0.23\end{array}$

$\begin{array}{lll}-0.48 & -0.87 & -0.09\end{array}$

$\begin{array}{lll}-0.74 & -1.13 & -0.36\end{array}$

$\begin{array}{lll}-1.67 & -2.48 & -0.86\end{array}$

$\begin{array}{lll}-1.21 & -1.86 & -0.56\end{array}$

$\begin{array}{lll}-0.41 & -0.85 & 0.03\end{array}$

$\begin{array}{lll}-0.54 & -0.82 & -0.26\end{array}$

$\begin{array}{lll}-0.28 & -0.75 & 0.2\end{array}$

$\begin{array}{lll}-0.31 & -0.85 & 0.22\end{array}$

$\begin{array}{lll}0.18 & -0.3 & 0.66\end{array}$

$\begin{array}{lll}-0.96 & -1.35 & -0.58\end{array}$

$\begin{array}{lll}-0.56 & -0.9 & -0.22\end{array}$

$\begin{array}{llll}-0.91 & -1.34 & -0.47\end{array}$

$\begin{array}{lll}-2.83 & -2.67 & -1\end{array}$

$\begin{array}{lll}-0.21 & -0.81 & 0.38\end{array}$

$\begin{array}{lll}-0.33 & -0.95 & 0.29\end{array}$

$\begin{array}{llll}-0.62 & -0.99 & -0.26\end{array}$

$\begin{array}{llll}-0.23 & -0.64 & 0.17\end{array}$

$\begin{array}{lll}-2.1 & -2.83 & -1.37\end{array}$

$\begin{array}{llll}-0.73 & -1.01 & -0.45\end{array}$

$\begin{array}{llll}-0.47 & -0.81 & -0.13\end{array}$

$\begin{array}{llll}-2.4 & -3.17 & -1.64\end{array}$

$\begin{array}{llll}0.64 & 0.48 & 0.81\end{array}$

$\begin{array}{llll}-0.69 & -1.11 & -0.27\end{array}$

$\begin{array}{llll}-1.19 & -2.04 & -0.35\end{array}$

$\begin{array}{lll}-0.79 & -1.37 & -0.21\end{array}$

$\begin{array}{lll}0.34 & -0.27 & 0.96\end{array}$

$\begin{array}{lll}-0.58 & -1.02 & -0.13\end{array}$

$\begin{array}{llll}-0.41 & -0.63 & -0.19\end{array}$

$\begin{array}{lll}-1.01 & -1.55 & -0.46\end{array}$

$\begin{array}{lll}0 & -0.46 & 0.46\end{array}$

$\begin{array}{lll}-0.69 & -1.21 & -0.17\end{array}$

$\begin{array}{lll}-0.4 & -0.95 & 0.16\end{array}$

$\begin{array}{lll}-0.02 & -0.61 & 0.56\end{array}$

$\begin{array}{lll}-0.57 & -0.97 & -0.18\end{array}$

\begin{tabular}{lll}
-1.44 & -1.92 & -0.95 \\
\hline
\end{tabular}

$\begin{array}{lll}-0.55 & -1.16 & 0.06\end{array}$

$\begin{array}{lll}-0.8 & -1.34 & -0.27\end{array}$

$\begin{array}{lll}-0.56 & -0.82 & 0.31\end{array}$

$\begin{array}{lll}-0.63 & -0.83 & -0.44\end{array}$

$\begin{array}{lll}-0.59 & -0.73 & -0.45\end{array}$ 


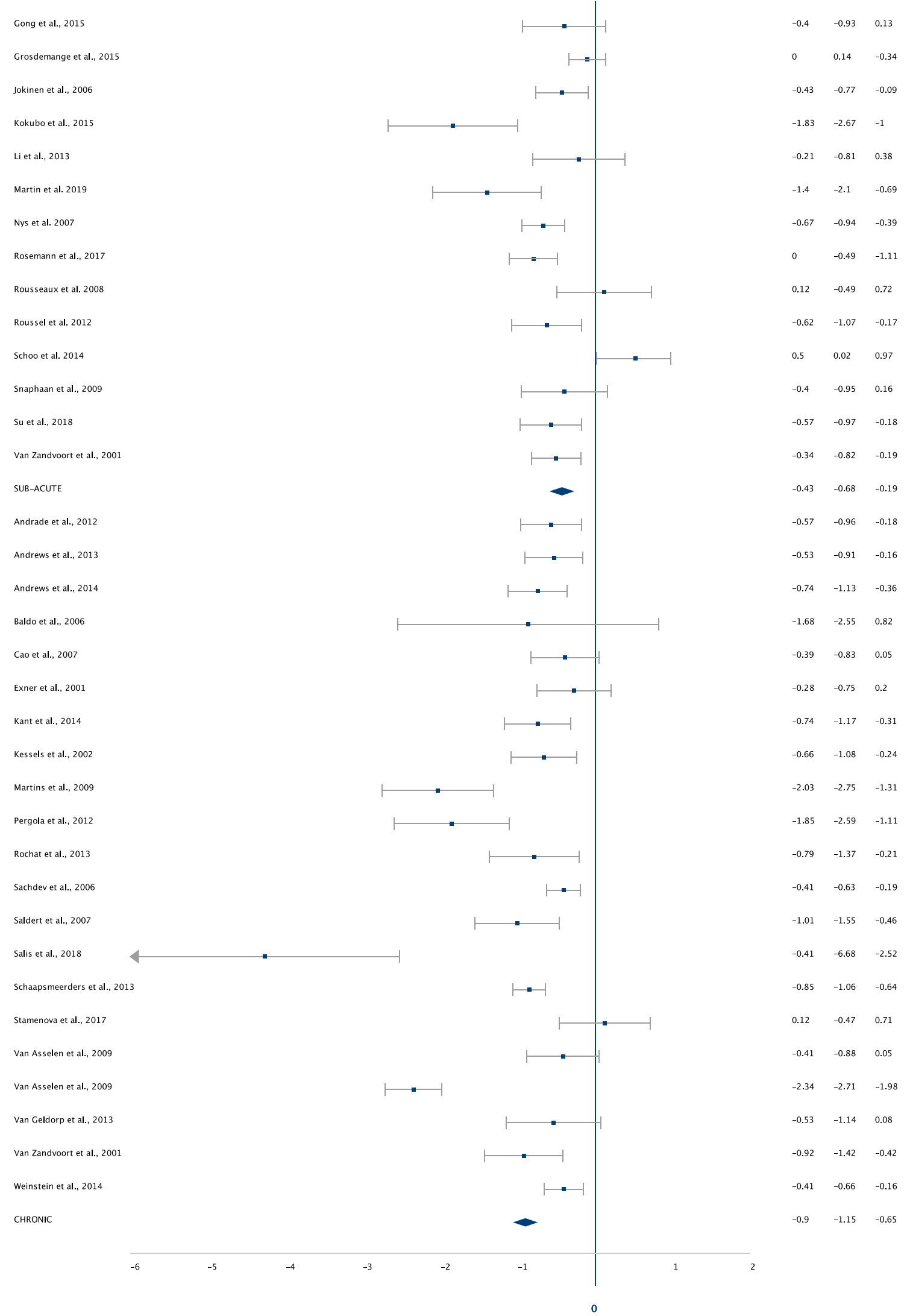

Fig. 5 Overall working memory performance categorized by interval between stroke and assessment (sub-acute $<3$ months and chronic) 
To minimize heterogeneity due to task variation, we reran the analysis including only studies with Digit Span or Spatial Span as working memory measure. Effect sizes were highly similar to those of the analysis including all studies for the overall, and low- and high-load analyses. The sub-analysis with patients in the sub-acute stage included only eight studies and yielded a lower effect size (Table S3b online supplemental materials).

\section{Qualitative Assessment of Studies Comparing Lesion Location and Longitudinal Studies}

This qualitative assessment includes 75 studies, 50 from the meta-analysis and 25 additional studies that were not taken into account in the meta-analysis due to missing statistics or overlapping samples. Sixteen percent of the studies $(k=12)$ compared working memory performance of patients with a left hemisphere stroke to patients with a right hemisphere stroke. Two-third of them $(66.7 \%, k=8)$ did not report a statistically significant difference in performance between left and right hemisphere stroke patients. Twenty-five percent $(k=3)$ reported a worse performance in left hemisphere stroke patients compared to right hemisphere stroke patients and controls on immediate serial recall tasks (Ho, Kong, \& Koon, 2018), on letter-number sequencing (Andrews, Halford, Shum, Maujean, Chappell, \& Birney, 2014), and on a visually presented digit span forward and backward task (Low, Crewther, Perre, Ong, Laycock, \& Wijeratne, 2016). One study (8.3\%) reported no difference in performance of left hemisphere stroke patients and controls but impaired performance in right hemisphere stroke patients on a backward spatial span task (Van der Ham, van Wezel, Oleksiak, van Zandvoort, Frijns, Kappelle, \& Postma, 2012).

A second comparison made in studies is between patients with an anterior and posterior lesion. Studies showed performance more strongly affected in patients with frontal lesions compared to posterior lesions on different forward span tasks (Roussel, Dujardin, Hénon, \& Godefroy, 2012), on digit span backward (but not forward, Leskelä et al., 1999), and on high-load n-back tasks (Andrews, Halford, Shum, Maujean, Chappell, \& Birney, 2013). In contrast, two studies reported the opposite; one reported performance in the posterior group to be inferior to patients with anterior lesions on digit span forward, with no differences on spatial span (Beeson, Bayles, Rubens, \& Kaszniak, 1993). The other study reported lower performance in patients with inferior parietal lesions compared to inferior frontal lesions on several forward span tasks (Baldo \& Dronkers, 2006).

Whereas 59 studies used neuroimaging to confirm stroke, to check for exclusion criteria and to describe the sample or to create subgroups, only seven studies related specific lesion locations to working memory performance. Spatial working memory performance was associated with lesions in the right posterior parietal and right dorsolateral prefrontal cortex and bilaterally in the hippocampal formation (Van Asselen, Kessels, Neggers, Kappelle, Frijns, \& Postma, 2006). Both parietal white matter and insula lesions were associated with spatial working memory deficits in neglect patients (Malhotra, Jäger, Parton, Greenwood, Playford, Brown, \& Husain, 2005). Not only spatial, but also verbal short-term memory was associated with parietal lesions. Lesions in the insula were in the same study associated with a lower performance in a musical working memory task (Hirel, Nighoghossian, Lévêque, Hannoun, Fornoni, Daligault, \& Caclin, 2017). Another study demonstrated that highload working memory tasks were associated with lesions in both the frontobasal and posterior centrum semi-ovale regions (Roussel et al., 2012). A study that only included patients with frontal lesions reported that the posterior part of the left middle frontal gyrus is significant for high-load but not for low-load working memory tasks (Volle, Kinkingnéhun, Pochon, Mondon, Thiebaut de Schotten, Seassau, \& Levy, 2008). A study with patients with cerebellar lesions attributed filtering of information in working memory tasks, but not working memory capacity, to specific areas of the cerebellum, such as the tonsil, the inferior semilunar lobule, and parts of the vermal pyramid (Baier, Müller, \& Dieterich, 2014). Finally, one study reported no predictive effect of lesion topography on memory. However, this study used a combined measure of spatial and verbal recall, recognition and working memory (Ramsey, Siegel, Lang, Strube, Shulman, \& Corbetta, 2017). Figure 6 shows how the results of these neuroimaging studies relate to each other.

Concerning timing of post-stroke working memory assessment, only four studies employed a longitudinal design. Three of these did not find any difference in performance of patients between the different time points. Two of these studies assessed the patients in the first week after stroke, with a follow up at three and six months respectively ( $\mathrm{Su}, \mathrm{Guo}$, Zhang, Zhou, Chen, Zhou, \& He, 2018; Van Zandvoort, De Haan, \& Kappelle, 2001a, b). The third study performed the first assessment between three and six months, with a threeyear follow-up (Sachdev, Chen, Brodaty, Thompson, Altendorf, \& Wen, 2009). The fourth study reported improved performance measured over three intervals; at two weeks, three months, and 12 months (Ramsey et al., 2017).

\section{Discussion}

This comprehensive review investigated working memory function post-stroke in comparison to healthy controls. A narrative and quantitative meta-analytic approach were combined. This allowed us to include studies of which we could not retrieve the necessary statistics for a meta-analysis but that did compare patients and controls on working 

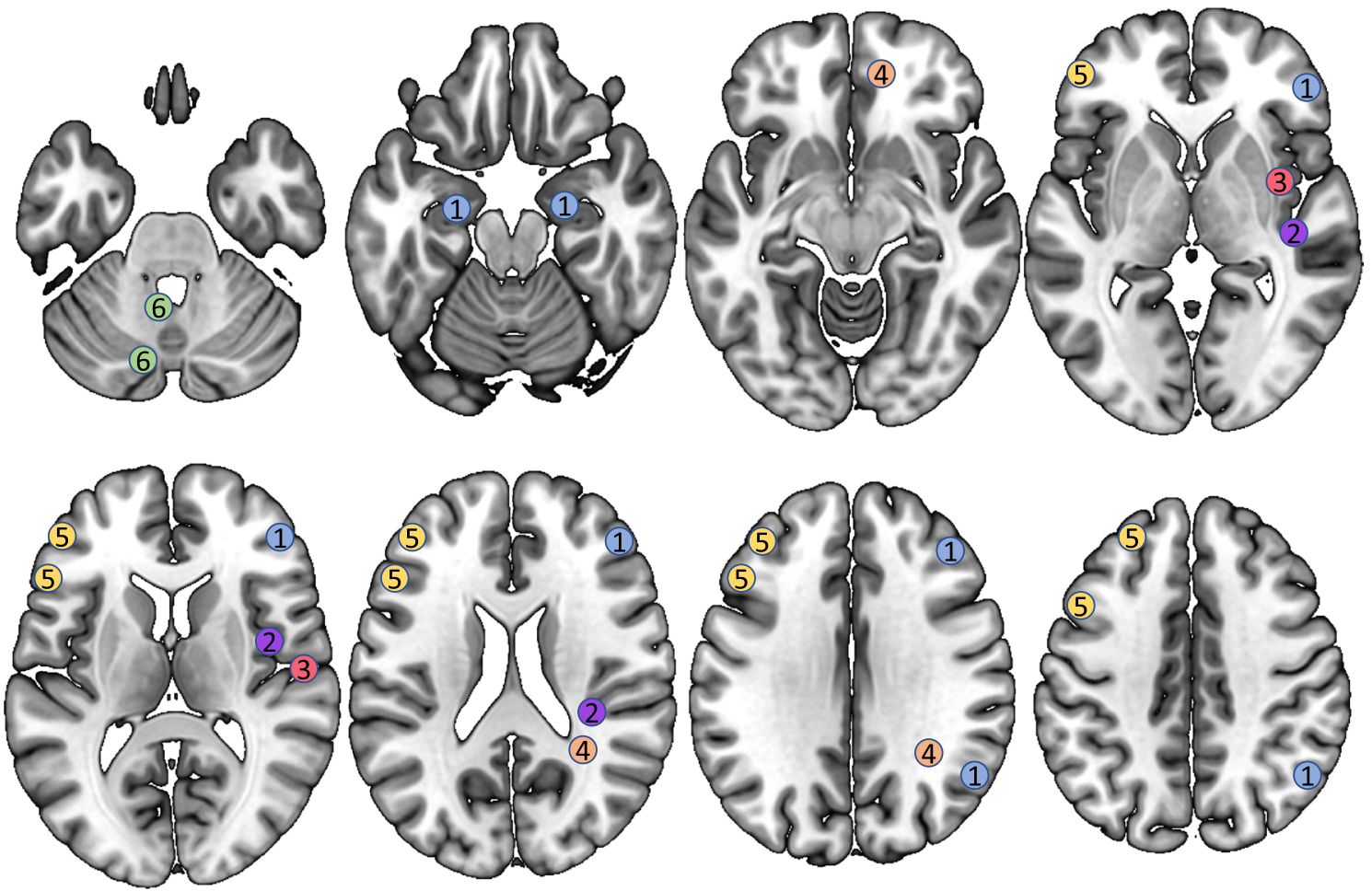

Fig. 6 Neural correlates associated with working memory performance. 1. Van Asselen et al., 2006, anatomical description: posterior parietal cortex and dorsolateral prefrontal cortex in the right hemisphere, hippocampal formation bilateral. 2. Malhotra et al., 2005, MNI coordinates: $x=35, y=-30, z=24 ; x=44, y=-12, z=16$, $x=43, y=-19, z=04$. 3. Hirel et al., 2017, MNI coordinates: $x=59$,

memory performance. A meta-analytic approach was used for quantification of severity of working memory deficits after stroke. In addition, it allowed for a comparison of the effect of high- and low-load conditions, and of verbal and non-verbal tasks, in the sub-acute and chronic stages. The literature was systematically reviewed to gain insight in the effect of lesion location on working memory and findings from longitudinal studies. Of the 75 studies incorporated in this review, 50 studies were included in the meta-analysis. The meta-analysis revealed a moderate overall effect size, indicating lower working memory performance in post-stroke patients relative to stroke-free controls.

Categorical analyses showed that performance on lowload working memory tasks was impaired to the same extent as the performance on high-load tasks. This is in line with the study by Roussel and colleagues (2012) who concluded in their study that working memory deficits are a consequence of reduced short-term memory capacity. Their conclusion is based on the finding that when controlling for verbal memory span, the impairment on working memory span disappeared. In terms of the model by Baddeley and Hitch (1974), this indicates impairment in stroke patients in the phonological loop and visuospatial sketchpad rather $y=-12, z=11 ; x=39, y=-2, z=-6.4$. Roussel et al., 2012, anatomical description: frontobasal and posterior centrum semi-ovale regions in the right hemisphere. 5. Volle et al., 2008, Brodmann areas: 6, 8, 9, 44, 45, 46. 6. Baier et al., 2014, MNI coordinates: $x=-6, y=-53$, $\mathrm{z}=-39 ; \mathrm{x}=-8, \quad \mathrm{y}=-73, \quad \mathrm{z}=-42 ; \mathrm{x}=-9, \quad \mathrm{y}=-71, \quad \mathrm{z}=-42 ;$ $x=-5, y=-67, z=-42$.

than the central executive. However, as most of the high load tasks are a form of backward span tasks, it can be argued that the tax on the central executive is low as the serial order stays the same and only needs to be reversed. Especially for spatial span tasks, it has been suggested that this process may only rely on the visuo-spatial sketchpad, as the visual pattern is not affected by reversing (e.g. Kessels, van Den Berg, Ruis, \& Brands, 2008; Wilde, Strauss, \& Tulsky, 2004). The few studies in this review that included tasks with higher demands (n-back tasks and letter-number sequencing) show inconsistent results Three out of seven studies had considerable larger effect sizes and four had effect sizes comparable to the mean. Based on the current limited evidence, we have no strong reason to assume an additive deficit in more complex processing. However, the question of whether stroke results in an additive deficit in the central executive under more demanding conditions needs further investigation.

Stroke seems to affect both slave systems, the phonological loop and the visuo-spatial sketchpad, to the same extent. Effect sizes were comparable for verbal and non-verbal tasks. Out of 12 studies that compared patients with left and right hemispheric stroke, eight did not report differences in 
performance based on hemisphere of the lesion. This is not in line with the theory of hemispheric specialization, which predicts more severe impairments in verbal working memory in patients with a left hemisphere stroke and more spatial working memory impairments in patients with right hemisphere stroke (e.g. Habib, Nyberg, \& Tulving, 2003). However, studies that did report a difference were in concordance with the theory of hemispheric specialization; one reported inferior performance in right hemisphere lesioned patients on a spatial task, three reported inferior performance on verbal tasks in patients with left hemisphere stroke. Based on the studies reviewed here we conclude that both frontal and non-frontal lesions, especially posterior parietal lesions, affect working memory performance. However, as with effect of hemisphere, there is no consensus on specialized areas depending on working memory task characteristics. A recent study indicates that whereas visual and motor deficits can be well explained by lesion characteristics, visual and verbal memory deficits are better predicted by measures of functional connectivity (Siegel, Ramsey, Snyder, Metcalf, Chacko, Weinberger, \& Corbetta, 2016). Our results support the view of a bilateral fronto-parietal network involved in working memory. Involvement of a widespread network might explain the high frequency of working memory deficits after stroke and the global nature of working memory impairment that we show in our meta-analysis.

Concerning the possible moderating effect of time between stroke and assessment, the meta-analysis and systematic review resulted in different conclusions. The meta-analysis showed a larger effect size in patients in the chronic stage of stroke compared to the sub-acute stage. This can be interpreted in different ways. First, remote effects may increase over time. A recent longitudinal study with MRI scans at one month, three months and twelve months after stroke, showed secondary degeneration in the limbic system and increased mean diffusivity after cortical stroke, independent of lesion location. The clinical outcome measure was the National Institutes of Health Stroke Scale (NIHSS) score, which did improve during the follow-up (Haque, Gabr, Hasan, George, Arevalo, Zha, \& Satani, 2019). No cognitive measures were taken in this study. Lower remote white matter integrity was related to worse long-term cognitive performance in a study with a follow-up 11 years after stroke (Schaapsmeerders, Tuladhar, Arntz, Franssen, Maaijwee, Rutten Jacobs, \& de Leeuw, 2016). Second, selection bias may play a role. In the acute stage, patients with more extensive lesions or severe aphasia are less likely to be included in research, whereas they may be able to participate in research months later. This might lead to underestimation of working memory deficits in the acute stage. In addition, patients with good recovery might not participate months after the event, because they resumed their daily activities. Of the four longitudinal studies included in our review, three showed impaired performance in working memory that remained stable up to three years after the event.
One longitudinal study showed spontaneous recovery with performance improving over the course of one year.

To pull apart these different explanations and gain more insight in the time-course of working memory deficits after stroke, more longitudinal research is needed. A limitation of the studies in the current meta-analysis is that they did not allow for a more fine-grained analysis of the effect of poststroke interval. As the range of intervals within studies was very high, a categorical comparison was more informative. A second study-related limitation is that many studies did not specify whether they included patients with pre-existing cognitive decline that could have influenced working memory performance. With respect to the current review, a limitation is that only Pubmed was used for the systematic search. Future studies should focus more on structural and functional connectivity in relation to working memory performance after stroke. These techniques could help to identify who is at risk for little spontaneous recovery or even deterioration in working memory and thereby guide rehabilitation programmes.

\section{Conclusion}

Taken together, this meta-analysis and systematic review clearly demonstrate the global nature of the impairment in working memory post-stroke. All subsystems of working memory are affected evidently and similar findings were reported for non-verbal and verbal tasks. Lesions in a widespread fronto-parietal network result in working memory impairment, which in turn results in a reduced capability to maintain verbal and non-verbal information. The finding that effect sizes are larger in the chronic stage compared to the sub-acute stage and that most longitudinal studies show no improvement in working memory performance, is important to take into account when discussing future prognosis with patients.

Supplementary Information The online version contains supplementary material available at (https://doi.org/10.1007/s11065-020-09462 $-4)$.

Funding This study was supported by an European Research Council (ERC) Advanced Grant (\#339374) awarded to E. H. F. de Haan.

\section{Compliance with ethical standard}

Conflict of interest None of the authors report potential conflicts of interest.

Open Access This article is licensed under a Creative Commons Attribution 4.0 International License, which permits use, sharing, adaptation, distribution and reproduction in any medium or format, as long as you give appropriate credit to the original author(s) and the source, provide a link to the Creative Commons licence, and indicate if changes were made. The images or other third party material in this article are 
Table 2 PRISMA Checklist

\begin{tabular}{llll}
\hline Section/topic & $\# \quad$ Checklist item & $\begin{array}{l}\text { Reported on } \\
\text { page \# }\end{array}$ & \multicolumn{1}{l}{}
\end{tabular}

\section{TITLE}

Title

\section{ABSTRACT}

Structured summary

\section{INTRODUCTION}

Rationale

Objectives

\section{METHODS}

Protocol and registration

Eligibility criteria

Information sources

Search

Study selection

Data collection process

Data items

Risk of bias in individual studies

Summary measures

Synthesis of results

Risk of bias across studies

Additional analyses

\section{RESULTS}

Study selection
1 Identify the report as a systematic review, meta-analysis, or both

2 Provide a structured summary including, as applicable: background; objectives; data sources; study eligibility criteria, participants, and interventions; study appraisal and synthesis methods; results; limitations; conclusions and implications of key findings; systematic review registration number

3 Describe the rationale for the review in the context of what is already known

4 Provide an explicit statement of questions being addressed with reference to participants, interventions, comparisons, outcomes, and study design (PICOS)

5 Indicate if a review protocol exists, if and where it can be accessed (e.g., Web address), and, if available, provide registration information including registration number

6 Specify study characteristics (e.g., PICOS, length of follow-up) 5, 6 and report characteristics (e.g., years considered, language, publication status) used as criteria for eligibility, giving rationale

7 Describe all information sources (e.g., databases with dates of coverage, contact with study authors to identify additional studies) in the search and date last searched

8 Present full electronic search strategy for at least one database, including any limits used, such that it could be repeated

9 State the process for selecting studies (i.e., screening, eligibility, included in systematic review, and, if applicable, included in the meta-analysis)

10 Describe method of data extraction from reports (e.g., piloted forms, independently, in duplicate) and any processes for obtaining and confirming data from investigators

11 List and define all variables for which data were sought (e.g., PICOS, funding sources) and any assumptions and simplifications made

12 Describe methods used for assessing risk of bias of individual studies (including specification of whether this was done at the study or outcome level), and how this information is to be used in any data synthesis

13 State the principal summary measures (e.g., risk ratio, difference in means)

14 Describe the methods of handling data and combining results of 8 studies, if done, including measures of consistency (e.g., $\mathrm{I}^{2}$ ) for each meta-analysis

15 Specify any assessment of risk of bias that may affect the cumulative evidence (e.g., publication bias, selective reporting within studies)

16 Describe methods of additional analyses (e.g., sensitivity or subgroup analyses, meta-regression), if done, indicating which were pre-specified

17 Give numbers of studies screened, assessed for eligibility, and included in the review, with reasons for exclusions at each stage, ideally with a flow diagram
Title page

1

\section{$2-4$}

4

N/A

$5-8$

5

Figure 1

$5-8$

$6-7$

7 and

Appendix 2

7, 8

Table S2 supplemental materials

8

9, Fig. 1 
Table 2 (continued)

\begin{tabular}{|c|c|c|c|}
\hline Section/topic & \# & Checklist item & $\begin{array}{l}\text { Reported on } \\
\text { page \# }\end{array}$ \\
\hline Study characteristics & 18 & $\begin{array}{l}\text { For each study, present characteristics for which data were } \\
\text { extracted (e.g., study size, PICOS, follow-up period) and } \\
\text { provide the citations }\end{array}$ & 9-10, Table S1 supplemental materials \\
\hline Risk of bias within studies & 19 & $\begin{array}{l}\text { Present data on risk of bias of each study and, if available, any } \\
\text { outcome level assessment (see item 12) }\end{array}$ & 11 and Table S2 supplemental materials \\
\hline Results of individual studies & 20 & $\begin{array}{l}\text { For all outcomes considered (benefits or harms), present, for } \\
\text { each study: (a) simple summary data for each intervention } \\
\text { group (b) effect estimates and confidence intervals, ideally } \\
\text { with a forest plot }\end{array}$ & 12-13, Table 1, Fig. 3-5 \\
\hline Synthesis of results & 21 & $\begin{array}{l}\text { Present results of each meta-analysis done, including confi- } \\
\text { dence intervals and measures of consistency }\end{array}$ & Table 1 \\
\hline Risk of bias across studies & 22 & $\begin{array}{l}\text { Present results of any assessment of risk of bias across studies } \\
\text { (see Item 15) }\end{array}$ & 11 and Fig. 2 \\
\hline Additional analysis & 23 & $\begin{array}{l}\text { Give results of additional analyses, if done (e.g., sensitivity or } \\
\text { subgroup analyses, meta-regression [see Item 16]) }\end{array}$ & $\begin{array}{l}\text { 12, } 13 \text {, Fig. } 3-5 \text {, Table } \mathrm{S} 3 \mathrm{a} \text {, b supple- } \\
\text { mental materials }\end{array}$ \\
\hline \multicolumn{4}{|l|}{ DISCUSSION } \\
\hline Summary of evidence & 24 & $\begin{array}{l}\text { Summarize the main findings including the strength of evidence } \\
\text { for each main outcome; consider their relevance to key groups } \\
\text { (e.g., healthcare providers, users, and policy makers) }\end{array}$ & $16-19$ \\
\hline Limitations & 25 & $\begin{array}{l}\text { Discuss limitations at study and outcome level (e.g., risk of } \\
\text { bias), and at review-level (e.g., incomplete retrieval of identi- } \\
\text { fied research, reporting bias) }\end{array}$ & 18,19 \\
\hline Conclusions & 26 & $\begin{array}{l}\text { Provide a general interpretation of the results in the context of } \\
\text { other evidence, and implications for future research }\end{array}$ & $16-19$ \\
\hline \multicolumn{4}{|l|}{ FUNDING } \\
\hline Funding & 27 & $\begin{array}{l}\text { Describe sources of funding for the systematic review and } \\
\text { other support (e.g., supply of data); role of funders for the } \\
\text { systematic review }\end{array}$ & Title page and 19 \\
\hline
\end{tabular}

included in the article's Creative Commons licence, unless indicated otherwise in a credit line to the material. If material is not included in the article's Creative Commons licence and your intended use is not permitted by statutory regulation or exceeds the permitted use, you will need to obtain permission directly from the copyright holder. To view a copy of this licence, visit http://creativecommons.org/licenses/by/4.0/.

\section{Appendix 1}

See Table 2.

\section{Appendix 2}

\section{Adapted RTI Item Bank for Assessing Risk of Bias and Confounding}

Q1. Are inclusion and exclusion criteria applied uniformly?

Consider patients vs. controls if applicable, otherwise individual patients

Q2. Is the recruitment strategy the same across individuals or study groups?
Consider patients vs. controls if applicable, otherwise individual patients

Q3. Is the selection of the comparison group adequate?

Age and education matched

Q5. Is the outcome assessor blinded to exposure status?

Assessor of cognitive function blinded for clinical status (stroke or not)?

Q6. Are valid and reliable measures implemented?

Reliable and conventional ascertainment of stroke?

Q7. Is the length of follow-up the same across individuals or study groups?

Delay from stroke to cognitive testing uniform for all individuals?

Q8. Is the impact of loss to follow-up assessed?

Only applicable if follow-up study

Q9. Are important primary outcomes reported?

Cognitive impairment

Timing of cognitive testing

Q13. Are important confounding variables taken into account in the design and analysis?

Stratified by level of importance: 
1 Age, level of education, prior stroke, pre-existing dementia.

2 Vascular risk factors, vascular brain damage, concurrent neuropsychiatric disturbances.

Q4, Q10, Q11, Q12 of the RTI item bank are not relevant to the included studies

\section{References}

Andrade, S. P. C. D., Brucki, S. M. D., Bueno, O. F. A., \& SiqueiraNeto, J. I. (2012). Neuropsychological performance in patients with subcortical stroke. Arquivos de Neuro-Psiquiatria, 70, 341-347. https://doi.org/10.1590/S0004-282X2012005000012

Andrews, G., Halford, G. S., Shum, D., Maujean, A., Chappell, M., \& Birney, D. (2013). Relational processing following stroke. Brain and Cognition, 81, 44-51. https://doi.org/10.1016/j. bandc.2012.09.003

Andrews, G., Halford, G. S., Shum, D. H., Maujean, A., Chappell, M., \& Birney, D. P. (2014). Verbal learning and memory following stroke. Brain Injury, 28, 442-447. https://doi.org/10.3109/ 02699052.2014 .888758

Baddeley, A. (2000). The episodic buffer: a new component of working memory? Trends in Cognitive Sciences, 4, 417-423. https://doi. org/10.1016/S1364-6613(00)01538-2

Baddeley, A. (2012). Working memory: theories, models, and controversies. Annual Review of Psychology, 63, 1-29. https://doi. org/10.1146/annurev-psych-120710-100422

Baddeley, A. D., \& Hitch, G. (1974). Working memory. In Psychology of Learning and Motivation (Vol. 8, pp. 47-89). Academic press. DOI:10.1016/S0079-7421(08)60452-1

Baddeley, A.D., Hitch, G.J. \& Allen, R.J. (2018) From short-term store to multicomponent working memory: The role of the modal model. Memory \& Cognition. DOI:https://doi.org/10.3758/ s13421-018-0878-5. [Epub ahead of print]

Baier, B., Müller, N. G., \& Dieterich, M. (2014). What part of the cerebellum contributes to a visuospatial working memory task? Annals of Neurology, 76, 754-757. https://doi.org/10.1002/ ana. 24272

Baldo, J. V., \& Dronkers, N. F. (2006). The role of inferior parietal and inferior frontal cortex in working memory. Neuropsychology, 20, 529. https://doi.org/10.1037/0894-4105.20.5.529

Beeson, P. M., Bayles, K. A., Rubens, A. B., \& Kaszniak, A. W. (1993). Memory impairment and executive control in individuals with stroke-induced aphasia. Brain and Language, 45, 253-275. https://doi.org/10.1006/brln.1993.1045

Bergmann, H. C., Kiemeneij, A., Fernández, G., \& Kessels, R. P. (2013). Early and late stages of working-memory maintenance contribute differentially to long-term memory formation. ActaPsychologica, 143, 181-190. https://doi.org/10.1016/j. actpsy.2013.02.009

Borenstein, M., Hedges, L. V., Higgins, J. P., \& Rothstein, H. R. (2011). Introduction to meta-analysis. John Wiley \& Sons.

Borenstein, M., Hedges, L., Higgins, J., Rothstein, H. (2005). Comprehensive Meta-analysis Version 2, Biostat, Englewood NJ.

Burton, E. J., Kenny, R. A., O’Brien, J., Stephens, S., Bradbury, M., Rowan, E., \& Ballard, C. (2004). White matter hyperintensities are associated with impairment of memory, attention, and global cognitive performance in older stroke patients. Stroke, 35, 12701275. https://doi.org/10.1161/01.STR.0000126041.99024.86

Butler, B. C., Lawrence, M., Eskes, G. A., \& Klein, R. (2009). Visual search patterns in neglect: Comparison of peripersonal and extrapersonal space. Neuropsychologia, 47, 869-878. https://doi. org/10.1016/j.neuropsychologia.2008.12.020

Cao, M., Ferrari, M., Patella, R., Marra, C., \& Rasura, M. (2007). Neuropsychological findings in young-adult stroke patients. Archives of Clinical Neuropsychology, 22, 133-142. https://doi. org/10.1016/j.acn.2006.09.005

Chai, W. J., Abd Hamid, A. I., \& Abdullah, J. M. (2018). Working Memory From the Psychological and Neurosciences Perspectives: A Review. Frontiers in Psychology, 9, 401. https://doi. org/10.3389/fpsyg.2018.00401

Chan, R. C., Shum, D., Toulopoulou, T., \& Chen, E. Y. (2008). Assessment of executive functions: Review of instruments and identification of critical issues. Archives of clinical neuropsychology, 23, 201-216. https://doi.org/10.1016/j.acn.2007.08.010

Clark-Carter, D. (2010). Quantitative psychological research: A student's handbook (3rd ed.). Hove, UK: Psychology Press.

Cohen, J. (1992). A power primer. Psychological Bulletin, 112, 155 159. https://doi.org/10.1037//0033-2909.112.1.155

Danet, L., Barbeau, E. J., Eustache, P., Planton, M., Raposo, N., Sibon, I., \& Pariente, J. (2015). Thalamic amnesia after infarct: the role of the mammillothalamic tract and mediodorsal nucleus. Neurology, 85, 2107-2115. https://doi.org/10.1212/WNL. 0000000000002226

De Haan, E. H., Nys, G. M., \& Van Zandvoort, M. J. (2006). Cognitive function following stroke and vascular cognitive impairment. Current Opinion in Neurology, 19, 559-564. https://doi. org/10.1097/01.wco.0000247612.21235.d9

DistillerSR Forest Plot Generator from Evidence Partners. https://www. evidencepartners.com/resources/forest-plot-generator/

Elwan, O., Hashem, S., Helmy, A. A., El Tamawy, M., Naseer, M. A., Elwan, F., \& El Tatawy, S. (1994). Cognitive deficits in ischemic strokes: psychometric, electrophysiological and cranial tomographic assessment. Journal of the Neurological Sciences, 125, 168-174. https://doi.org/10.1016/0022-510X(94)90030-2

Exner, C., Weniger, G., \& Irle, E. (2001). Implicit and explicit memory after focal thalamic lesions. Neurology, 57, 2054-2063. https:// doi.org/10.1212/WNL.57.11.2054

Friedman, N. P., \& Miyake, A. (2017). Unity and diversity of executive functions: Individual differences as a window on cognitive structure. Cortex, 86, 186-204. https://doi.org/10.1016/j. cortex.2016.04.023

Fu, X., Lu, Z., Wang, Y., Huang, L., Wang, X., Zhang, H., \& Xiao, Z. (2017). A Clinical Research Study of Cognitive Dysfunction and Affective Impairment after Isolated Brainstem Stroke. Frontiers in Aging Neuroscience, 9, 400. https://doi.org/10.3389/ fnagi.2017.00400

Godefroy, O., Rousseaux, M., Pruvo, J. P., Cabaret, M., \& Leys, D. (1994). Neuropsychological changes related to unilateral lenticulostriate infarcts. Journal of Neurology, Neurosurgery \& Psychiatry, 57, 480-485. https://doi.org/10.1136/jnnp.57.4.480

Gong, L., Wang, J., Feng, L., Wang, M., Li, X., Hu, J., \& Wang, K. (2015). Explicit memory and implicit memory in occipital lobe stroke patients. Journal of Stroke and Cerebrovascular Diseases, 24, 663-667. https://doi.org/10.1016/j. jstrokecerebrovasdis.2014.10.018

Gorišek, V. R., Isoski, V. Z., Belič, A., Manouilidou, C., Koritnik, B., Bon, J., \& Zidar, J. (2016). Beyond aphasia: Altered EEG connectivity in Broca's patients during working memory task. Brain and Language, 163, 10-21. https://doi.org/10.1016/j. band1.2016.08.003

Grosdemange, A., Monfort, V., Richard, S., Toniolo, A. M., Ducrocq, X., \& Bolmont, B. (2015). Impact of anxiety on verbal and visuospatial working memory in patients with acute stroke without severe cognitive impairment. Journal of Neurology, Neurosurgery \& Psychiatry, 86, 513-519. https://doi.org/10.1136/jnnp2014-308232 
Habib, R., Nyberg, L., \& Tulving, E. (2003). Hemispheric asymmetries of memory: the HERA model revisited. Trends in Cognitive Sciences, 7, 241-245. https://doi.org/10.1016/ S1364-6613(03)00110-4

Haque, M. E., Gabr, R. E., Hasan, K. M., George, S., Arevalo, O. D., Zha, A., \& Satani, N. (2019). Ongoing Secondary Degeneration of the Limbic System in Patients With Ischemic Stroke: A Longitudinal MRI Study. Frontiers in Neurology, 10. https://doi. org/10.3389/fneur.2019.00154

Hedges, L. V., \& Olkin, I. (1985). Statistical methods for meta-analysis. Orlando, FL: Academic Press.

Heil, M., Rösler, F., \& Rolke, B. (2003). Another artificial division and the data don't support it. Behavioral and Brain Sciences, 26, 739-740. https://doi.org/10.1017/S0140525X0333016X

Hirel, C., Nighoghossian, N., Lévêque, Y., Hannoun, S., Fornoni, L., Daligault, S., \& Caclin, A. (2017). Verbal and musical short-term memory: Variety of auditory disorders after stroke. Brain and Cognition, 113, 10-22. https://doi.org/10.1016/j. bandc.2017.01.003

Ho, D. W. L., Kong, A. P. H., \& Koon, N. T. (2018). Verbal short-term memory and language impairments in Cantonese speakers after stroke. International Journal of Speech-Language Pathology, 20(4), 383-392. https://doi.org/10.1080/17549507.2017.1287218

Hochstenbach, J., Mulder, T., van Limbeek, J., Donders, R., \& Schoonderwaldt, H. (1998). Cognitive decline following stroke: a comprehensive study of cognitive decline following stroke. Journal of Clinical and Experimental Neuropsychology, 20(4), 503-517. https://doi.org/10.1076/jcen.20.4.503.1471

Hochstenbach, J., van Spaendonck, K. P., Cools, A. R., Horstink, M. W., \& Mulder, T. (1998). Cognitive deficits following stroke in the basal ganglia. Clinical Rehabilitation, 12(6), 514-520. https://doi.org/10.1191/026921598666870672

Ignjatovic, V. B., Semnic, M., Bukurov, K. G., \& Kozic, D. (2015). Cognitive impairment and functional ability in the acute phase of ischemic stroke. European Review for Medical and Pharmacological Sciences, 19, 3251-3256.

Jokinen, H., Kalska, H., Mäntylä, R., Pohjasvaara, T., Ylikoski, R., Hietanen, M., \& Erkinjuntti, T. (2006). Cognitive profile of subcortical ischaemic vascular disease. Journal of Neurology, Neurosurgery \& Psychiatry, 77, 28-33. https://doi.org/10.1136/ jnnp.2005.069120

Kant, N., van den Berg, E., van Zandvoort, M. J., Frijns, C. J., Kappelle, L. J., \& Postma, A. (2014). Functional correlates of prospective memory in stroke. Neuropsychologia, 60, 77-83. https://doi.org/10.1016/j.neuropsychologia.2014.05.015

Karimian, N., Asgari, K., NeshatDoost, H. T., Oreizi, H. R., \& Najafi, M. R. (2018). Investigating patterns of memory impairment in ischemic stroke in an iranian population. Applied Neuropsychology: Adult, 25(5), 458-463. https://doi.org/10.1080/ 23279095.2017.1329144

Kessels, R. P., Kappelle, L. J., de Haan, E. H., \& Postma, A. (2002). Lateralization of spatial-memory processes: evidence on spatial span, maze learning, and memory for object locations. Neuropsychologia, 40(8), 1465-1473. https://doi.org/10.1016/ S0028-3932(01)00199-3

Kessels, R. P., van Den Berg, E., Ruis, C., \& Brands, A. M. (2008). The backward span of the Corsi Block-Tapping Task and its association with the WAIS-III Digit Span. Assessment, 15(4), 426-434. https://doi.org/10.1177/1073191108315611

Kober, S. E., Schweiger, D., Witte, M., Reichert, J. L., Grieshofer, P., Neuper, C., \& Wood, G. (2015). Specific effects of EEG based neurofeedback training on memory functions in post-stroke victims. Journal of Neuroengineering and Rehabilitation, 12(1), 107. https://doi.org/10.1186/s12984-015-0105-6

Kokubo, K., Suzuki, K., Hattori, N., Miyai, I., \& Mori, E. (2015). Executive dysfunction in patients with putaminal hemorrhage.
Journal of Stroke and Cerebrovascular Diseases, 24(9), 19781985. https://doi.org/10.1016/j.jstrokecerebrovasdis.2015.04.047

Kraft, A., Irlbacher, K., Finke, K., Kaufmann, C., Kehrer, S., Liebermann, D., \& Brandt, S. A. (2015). Dissociable spatial and non-spatial attentional deficits after circumscribed thalamic stroke. Cortex, 64, 327-342. https://doi.org/10.1016/j. cortex.2014.12.005

Leskelä, M., Hietanen, M., Kalska, H., Ylikoski, R., Pohjasvaara, T., Mäntylä, R., \& Erkinjuntti, T. (1999). Executive functions and speed of mental processing in elderly patients with frontal or nonfrontal ischemic stroke. European Journal of Neurology, 6, 653-661. https://doi.org/10.1046/j.1468-1331.1999.660653.x

Li, R., Wang, S., Zhu, L., Guo, J., Zeng, L., Gong, Q., \& Chen, H. (2013). Aberrant functional connectivity of resting state networks in transient ischemic attack. PLOS ONE, 8, e71009. https://doi.org/10.1371/journal.pone.0071009

Li, J., You, S. J., Xu, Y. N., Yuan, W., Shen, Y., Huang, J. Y., \& Liu, C. F. (2019). Cognitive impairment and sleep disturbances after minor ischemic stroke. Sleep and Breathing, 1-8. https://doi. org/10.1007/s11325-018-1709-4

Liebermann, D., Ploner, C. J., Kraft, A., Kopp, U. A., \& Ostendorf, F. (2013). A dysexecutive syndrome of the medial thalamus. Cortex, 49(1), 40-49. https://doi.org/10.1016/j.cortex.2011.11.005

Lim, C., \& Alexander, M. P. (2009). Stroke and episodic memory disorders. Neuropsychologia, 47(14), 3045-3058. https://doi. org/10.1016/j.neuropsychologia.2009.08.002

Low, E., Crewther, S. G., Perre, D. L., Ong, B., Laycock, R., Tu, H., $\&$ Wijeratne, T. (2016). Beyond neglect: preliminary evidence of retrospective time estimation abnormalities in non-neglect stroke and transient ischemic attack patients. Scientific Reports, 6, 22598. https://doi.org/10.1038/srep22598

Luukkainen-Markkula, R., Tarkka, I. M., Pitkänen, K., Sivenius, J., \& Hämäläinen, H. (2011). Hemispatial neglect reflected on visual memory. Restorative Neurology and Neuroscience, 29(5), 321330. https://doi.org/10.3233/RNN-2011-0602

Malhotra, P., Jäger, H. R., Parton, A., Greenwood, R., Playford, E. D., Brown, M. M., \& Husain, M. (2005). Spatial working memory capacity in unilateral neglect. Brain, 128(2), 424-435. https:// doi.org/10.1093/brain/awh372

Malm, J., Kristensen, B., Karlsson, T., Carlberg, B., Fagerlund, M., \& Olsson, T. (1998). Cognitive impairment in young adults with infratentorial infarcts. Neurology, 51, 433-440. https://doi. org/10.1212/WNL.51.2.433

Malouin, F., Belleville, S., Richards, C. L., Desrosiers, J., \& Doyon, J. (2004). Working memory and mental practice outcomes after stroke1. Archives of Physical Medicine and Rehabilitation, 85, 177-183. https://doi.org/10.1016/S0003-9993(03)00771-8

Mansueti, L., De Frias, C. M., Bub, D., \& Dixon, R. A. (2008). Exploring cognitive effects of self reported mild stroke in older adults: selective but robust effects on story memory. Aging, Neuropsychology, and Cognition, 15, 545-573. https://doi. org/10.1080/13825580701858216

Martin, R. C., \& Schnur, T. T. (2019). Independent contributions of semantic and phonological working memory to spontaneous speech in acute stroke. Cortex, 112, 58-68. https://doi. org/10.1016/j.cortex.2018.11.017

Martins, F. C., \& Ortiz, K. Z. (2009). The relationship between working memory and apraxia of speech. Arquivos de NeuroPsiquiatria, 67, 843-848. https://doi.org/10.1590/S0004282X2009000500012

McDonnell, M. N., Bryan, J., Smith, A. E., \& Esterman, A. J. (2011). Assessing cognitive impairment following stroke. Journal of Clinical and Experimental Neuropsychology, 33, 945-953. https://doi.org/10.1080/13803395.2011.575769

Mellon, L., Brewer, L., Hall, P., Horgan, F., Williams, D., \& Hickey, A. (2015). Cognitive impairment six months after ischaemic stroke: 
a profile from the ASPIRE-S study. BMC neurology, 15, 31. https://doi.org/10.1186/s12883-015-0288-2

Moher, D., Liberati, A., Tetzlaff, J., Altman, D.G., The PRISMA Group. (2009). Preferred reporting items for systematic reviews and meta-analyses: The PRISMA statement. PLoS Medicine, 6, e1000097. https://doi.org/10.1371/journal.pmed.1000097

Nobre, A. D. P., Rodrigues, J. D. C., Sbicigo, J. B., Piccolo, L. D. R., Zortea, M., Junior, S. D., \& de Salles, J. F. (2013). Tasks for assessment of the episodic buffer: A systematic review. Psychology \& Neuroscience, 6, 331. https://doi.org/10.3922/j. psns.2013.3.10

Nys, G. M. S., Van Zandvoort, M. J. E., De Kort, P. L. M., Jansen, B. P. W., De Haan, E. H. F., \& Kappelle, L. J. (2007). Cognitive disorders in acute stroke: prevalence and clinical determinants. Cerebrovascular Diseases, 23, 408-416. https://doi. org/10.1159/000101464

Nys, G. M. S., Van Zandvoort, M., Worp, H. V. D., Kappelle, L. J., \& Haan, E. D. (2006). Neuropsychological and neuroanatomical correlates of perseverative responses in subacute stroke. Brain, 129, 2148-2157. https://doi.org/10.1093/brain/awl199

Oliveira, C. R. D., Pagliarin, K. C., Calvette, L. D. F., Gindri, G., Argimon, I. I. D. L., \& Fonseca, R. P. (2015). Depressive signs and cognitive performance in patients with a right hemisphere stroke. In CoDAS (Vol. 27, No. 5, pp. 452-457). Sociedade Brasileira de Fonoaudiologia. DOI:https://doi.org/10.1590/2317-1782/ 20152015005

Pendlebury, S. T., \& Rothwell, P. M. (2009). Prevalence, incidence, and factors associated with pre-stroke and post-stroke dementia: a systematic review and meta-analysis. The Lancet Neurology, 8, 1006-1018. https://doi.org/10.1016/S1474-4422(09)70236-4

Pergola, G., Güntürkün, O., Koch, B., Schwarz, M., Daum, I., \& Suchan, B. (2012). Recall deficits in stroke patients with thalamic lesions covary with damage to the parvocellularmediodorsal nucleus of the thalamus. Neuropsychologia, 50, 2477-2491. https://doi.org/10.1016/j.neuropsychologia.2012.06.019

Piccardi, L., Matano, A., D’Antuono, G., Marin, D., Ciurli, P., Incoccia, C., \& Guariglia, P. (2016). Persistence of gender related-effects on visuo-spatial and verbal working memory in right brain-damaged patients. Frontiers in Behavioral Neuroscience, 10, 139. https://doi.org/10.3389/fnbeh.2016.00139

Planton, M., Peiffer, S., Albucher, J. F., Barbeau, E. J., Tardy, J., Pastor, J., \& Demonet, J. F. (2012). Neuropsychological outcome after a first symptomatic ischaemic stroke with "good recovery." European Journal of Neurology, 19, 212-219. https://doi.org/ 10.1111/j.1468-1331.2011.03450.x

Pluta, A., Gawron, N., Sobańska, M., Wójcik, A. D., \& Łojek, E. (2017). The nature of the relationship between neurocognition and theory of mind impairments in stroke patients. Neuropsychology, 31, 666. https://doi.org/10.1037/neu0000379

Ramsey, L. E., Siegel, J. S., Lang, C. E., Strube, M., Shulman, G. L., \& Corbetta, M. (2017). Behavioural clusters and predictors of performance during recovery from stroke. Nature Human Behaviour, 1, 0038. https://doi.org/10.1038/s41562-016-0038

Rapport, L. J., Webster, J. S., \& Dutra, R. L. (1994). Digit span performance and unilateral neglect. Neuropsychologia, 32, 517-525. https://doi.org/10.1016/0028-3932(94)90141-4

Ravizza, S. M., McCormick, C. A., Schlerf, J. E., Justus, T., Ivry, R. B., \& Fiez, J. A. (2005). Cerebellar damage produces selective deficits in verbal working memory. Brain, 129(2), 306-320. https://doi.org/10.1093/brain/awh685

Rochat, L., Van der Linden, M., Renaud, O., Epiney, J. B., Michel, P., Sztajzel, R., \& Annoni, J. M. (2013). Poor reward sensitivity and apathy after stroke Implication of basal ganglia. Neurology, 81, 1674-1680. https://doi.org/10.1212/01.wnl. $0000435290.49598 .1 \mathrm{~d}$
Rosemann, S., Brunner, F., Kastrup, A., \& Fahle, M. (2017). Musical, visual and cognitive deficits after middle cerebral artery infarction. eNeurologicalSci, 6, 25-32. DOI:https://doi. org/10.1016/j.ensci.2016.11.006

Rousseaux, M., Cabaret, M., Serafi, R., \& Kozlowski, O. (2008). An evaluation of cognitive disorders after anterior choroidal artery infarction. Journal of Neurology, 255, 1405. https://doi. org/10.1007/s00415-008-0931-6

Roussel, M., Dujardin, K., Hénon, H., \& Godefroy, O. (2012). Is the frontal dysexecutive syndrome due to a working memory deficit? Evidence from patients with stroke. Brain, 135, 21922201. https://doi.org/10.1093/brain/aws132

Sachdev, P. S., Brodaty, H., Valenzuela, M. J., Lorentz, L., Looi, J. C. L., Berman, K., \& Zagami, A. S. (2006). Clinical determinants of dementia and mild cognitive impairment following ischaemic stroke: the Sydney Stroke Study. Dementia and Geriatric Cognitive Disorders, 21, 275-283. https://doi. org/10.1159/000091434

Sachdev, P. S., Chen, X., Brodaty, H., Thompson, C., Altendorf, A., $\&$ Wen, W. (2009). The determinants and longitudinal course of post-stroke mild cognitive impairment. Journal of the International Neuropsychological Society, 15, 915-923. https://doi. org/10.1017/S1355617709990579

Saldert, C., \& Ahlsén, E. (2007). Inference in right hemisphere damaged individuals' comprehension: The role of sustained attention. Clinical Linguistics \& Phonetics, 21, 637-655. https://doi. org/10.1080/02699200701431056

Salis, C., Martin, N., Meehan, S. V., \& McCaffery, K. (2018). Shortterm memory span in aphasia: Insights from speech-timing measures. Journal of Neurolinguistics, 48, 176-189. https://doi. org/10.1016/j.jneuroling.2018.04.014

Saxena, S. K., Ng, T. P., Koh, G., Yong, D., \& Fong, N. P. (2007). Is improvement in impaired cognition and depressive symptoms in post-stroke patients associated with recovery in activities of daily living? ActaNeurologicaScandinavica, 115, 339-346. https://doi. org/10.1111/j.1600-0404.2006.00751.x

Schaapsmeerders, P., Maaijwee, N. A., van Dijk, E. J., Rutten-Jacobs, L. C., Arntz, R. M., Schoonderwaldt, H. C., \& de Leeuw, F. E. (2013). Long-term cognitive impairment after first-ever ischemic stroke in young adults. Stroke, 44, 1621-1628. https:// doi.org/10.1161/STROKEAHA.111.000792

Schaapsmeerders, P., Tuladhar, A. M., Arntz, R. M., Franssen, S., Maaijwee, N. A., Rutten-Jacobs, L. C., \& de Leeuw, F. E. (2016). Remote lower white matter integrity increases the risk of long-term cognitive impairment after ischemic stroke in young adults. Stroke, 47, 2517-2525. https://doi.org/10.1161/ STROKEAHA.116.014356

Schweinberger, S. R., Buse, C., Freeman, R. B., Jr., Schönle, P. W., \& Sommer, W. (1992). Memory search for faces and digits in patients with unilateral brain lesions. Journal of clinical and experimental neuropsychology, 14, 839-856. https://doi. org/10.1080/01688639208402866

Selnes, P., Grambaite, R., Rincon, M., Bjørnerud, A., Gjerstad, L., Hessen, E., \& Vegge, K. (2015). Hippocampal complex atrophy in poststroke and mild cognitive impairment. Journal of Cerebral Blood Flow \& Metabolism, 35, 1729-1737. https://doi. org/10.1038/jcbfm.2015.110

Siegel, J. S., Ramsey, L. E., Snyder, A. Z., Metcalf, N. V., Chacko, R. V., Weinberger, K., \& Corbetta, M. (2016). Disruptions of network connectivity predict impairment in multiple behavioral domains after stroke. Proceedings of the National Academy of Sciences, 113, E4367-E4376. https://doi.org/10.1073/ pnas. 1521083113

Snaphaan, L., Rijpkema, M., Uden, I. V., Fernandez, G., \& de Leeuw, F. E. (2009). Reduced medial temporal lobe functionality in 
stroke patients: a functional magnetic resonance imaging study. Brain, 132, 1882-1888. https://doi.org/10.1093/brain/awp133

Srikanth, V. K., Thrift, A. G., Saling, M. M., Anderson, J. F., Dewey, H. M., Macdonell, R. A., \& Donnan, G. A. (2003). Increased risk of cognitive impairment 3 months after mild to moderate firstever stroke: a Community-Based Prospective Study of Nonaphasic English-Speaking Survivors. Stroke, 34, 1136-1143. https:// doi.org/10.1161/01.STR.0000069161.35736.39

Stamenova, V., Jennings, J. M., Cook, S. P., Gao, F., Walker, L. A., Smith, A. M., \& Davidson, P. S. (2017). Repetition-lag memory training is feasible in patients with chronic stroke, including those with memory problems. Brain Injury, 31, 57-67. https:// doi.org/10.1080/02699052.2016.1222081

Stricker, N. H., Tybur, J. M., Sadek, J. R., \& Haaland, K. Y. (2010). Utility of the Neuropsychological Assessment Battery in detecting cognitive impairment after unilateral stroke. Journal of the International Neuropsychological Society, 16, 813-821. https:// doi.org/10.1017/S1355617710000652

Su, W., Guo, J., Zhang, Y., Zhou, J., Chen, N., Zhou, M., \& He, L. (2018). A Longitudinal Functional Magnetic Resonance Imaging Study of Working Memory in Patients Following a Transient Ischemic Attack: A Preliminary Study. Neuroscience Bulletin, 34, 963-971. https://doi.org/10.1007/s12264-018-0270-2

Synhaeve, N. E., Schaapsmeerders, P., Arntz, R. M., Maaijwee, N. A., Rutten-Jacobs, L. C., Schoonderwaldt, H. C., \& de Leeuw, F. E. (2015). Cognitive performance and poor long-term functional outcome after young stroke. Neurology, 85, 776-782. https://doi. org/10.1212/WNL.0000000000001882

Rosenthal, R. (1991). Applied social research methods series, Vol. 6. Meta-analytic procedures for social research (Rev. ed.).

Van Asselen, M., Kessels, R. P., Frijns, C. J., Kappelle, L. J., Neggers, S. F., \& Postma, A. (2009). Object-location memory: a lesionbehavior mapping study in stroke patients. Brain and Cognition, 71, 287-294. https://doi.org/10.1016/j.bandc.2009.07.012

Van Asselen, M., Kessels, R. P., Neggers, S. F., Kappelle, L. J., Frijns, C. J., \& Postma, A. (2006). Brain areas involved in spatial working memory. Neuropsychologia, 44, 1185-1194. https://doi. org/10.1016/j.neuropsychologia.2005.10.005

Van der Ham, I. J., van Wezel, R. J., Oleksiak, A., van Zandvoort, M. J., Frijns, C. J., Kappelle, L. J., \& Postma, A. (2012). The effect of stimulus features on working memory of categorical and coordinate spatial relations in patients with unilateral brain damage. Cortex, 48, 737-745. https://doi.org/10.1016/j. cortex.2011.03.002
Van Geldorp, B., Kessels, R. P., \& Hendriks, M. P. (2013). Single-item and associative working memory in stroke patients. Behavioural Neurology, 26, 199-201. https://doi.org/10.1155/2013/516804

Van Rooij, F. G., Kessels, R. P., Richard, E., De Leeuw, F. E., \& van Dijk, E. J. (2016). Cognitive impairment in transient ischemic attack patients: a systematic review. Cerebrovascular Diseases, 42(1-2), 1-9. https://doi.org/10.1159/000444282

Van Zandvoort, M. J., De Haan, E. H., \& Kappelle, L. J. (2001). Chronic cognitive disturbances after a single supratentorial lacunar infarct. Cognitive and Behavioral Neurology, 14, 98-102.

Van Zandvoort, M. J., De Haan, E. H., \& Kappelle, L. J. (2001). Single supratentorial lacunar infarcts may cause a decrease in cognitive capacity. (Unpublished doctoral dissertation). University of Utrecht, Utrecht The Netherlands.

Viswanathan, M., \& Berkman, N. D. (2012). Development of the RTI item bank on risk of bias and precision of observational studies. Journal of Clinical Epidemiology, 65, 163-178. https://doi. org/10.1016/j.jclinepi.2011.05.008

Viswanathan, M., Berkman, N. D., Dryden, D. M., \& Hartling, L. (2013). Assessing Risk of Bias and Confounding in Observational Studies of Interventions or Exposures: Further Development of the RTI Item Bank. Rockville, Agency for Healthcare Research and Quality (US). Report No.: 13-EHC106-EF.

Weinstein, G., Preis, S. R., Beiser, A. S., Au, R., Kelly-Hayes, M., Kase, C. S., \& Seshadri, S. (2014). Cognitive performance after stroke-The Framingham Heart Study. International Journal of Stroke, 9, 48-54. https://doi.org/10.1111/ijs.12275

Wilde, N. J., Strauss, E., \& Tulsky, D. S. (2004). Memory span on the Wechsler scales. Journal of Clinical and Experimental Neuropsychology, 26(4), 539-549. https://doi.org/10.1080/ 13803390490496605

Volle, E., Kinkingnéhun, S., Pochon, J. B., Mondon, K., Thiebaut de Schotten, M., Seassau, M., \& Levy, R. (2008). The functional architecture of the left posterior and lateral prefrontal cortex in humans. Cerebral Cortex, 18(10), 2460-2469. https://doi. org/10.1093/cercor/bhn010

Publisher's Note Springer Nature remains neutral with regard to jurisdictional claims in published maps and institutional affiliations. 